\title{
Impact of oral health on quality of life among the elderly population of Joaçaba, Santa Catarina, Brazil
}

\section{Impacto da condição bucal na qualidade de vida dos idosos de Joaçaba, Santa Catarina, Brasil}

\author{
Maria Gabriela Haye Biazevic* \\ Edgard Michel-Crosato** \\ Fabiola Iagher*** \\ Cleiton Eduardo Pooter**** \\ Silvia Letícia Correa**** \\ Cláudia Elisa Grasel $1^{* * * *}$
}

\begin{abstract}
The objective of this study was to investigate the impact of oral health conditions on the quality of life of elderly people in Joaçaba - SC, in Southern Brazil. A survey based on systematic sampling of clusters was carried out with 183 elderly people that belong to old age groups. The survey was conducted in order to assess the oral conditions of the participants (use of and need for prosthesis) based on the criteria from the World Health Organization publication "Oral Health Surveys, Basic Methods", $4^{\text {th }}$ edition. The oral health impact profile (OHIP) was used to evaluate the impact of oral condition in the quality of life. ABIPEME (Brazilian Association of Market Research Institutes) criterion was used, together with the level of education and the number of people in the household to determine social inequalities. The participants were mostly women (82\%) and the OHIP mean was 10.35 . No correlation was observed between the OHIP level and formal education or between OHIP and number of residents per household. There was a correlation of $0.240(p=0.001)$ between ABIPEME and OHIP. The OHIP mean for those not using maxillary prosthesis was 12.48 and the mean for those using it was $9.81(\mathrm{p}=0.399)$. The mean OHIP for those in need of maxillary prosthesis for those who did not need it was 13.00 and 8.88, respectively $(p=0.014)$. The same trend was found for the use and need for mandibular prosthesis. The conclusion was that the need for maxillary and mandibular prosthesis impacted the quality of life among the elderly population of Joaçaba.
\end{abstract}

DESCRIPTORS: Quality of life; Oral health; Geriatrics; Health surveys.

\begin{abstract}
RESUMO: O objetivo do presente estudo foi investigar o impacto da condição bucal na qualidade de vida dos idosos do município de Joaçaba - SC. Foi estudada a população de idosos que participa dos grupos da terceira idade a partir de amostra sistemática por conglomerados de 183 idosos. Foi realizado um levantamento epidemiológico utilizando os critérios de diagnóstico da OMS (Organização Mundial da Saúde) (1997) para verificar a condição bucal dos participantes (uso e necessidades de prótese). Foi aplicado o OHIP (Oral Health Impact Profile) para verificar o impacto da condição bucal na qualidade de vida. Para verificar a desigualdade social, foram utilizados critério ABIPEME (Associação Brasileira dos Institutos de Pesquisa de Mercado), grau de escolaridade e número de pessoas que moram no domicílio. A maioria dos participantes era do sexo feminino (82\%), e a média do OHIP foi de 10,35. Não se observou correlação entre OHIP e grau de escolaridade e OHIP e número de moradores por domicílio. Verificou-se correlação de 0,240 (p=0,001) entre OHIP e ABIPEME. A média do OHIP para as pessoas que não usavam prótese superior foi de $12,48 \mathrm{e}$, para os que usavam, 9,81 ( $\mathrm{p}=0,399)$. O OHIP médio para os que necessitavam de prótese superior foi de 13,00 e 8,88 para os que não necessitavam ( $p=0,014)$. Foi verificada a mesma tendência para uso e necessidades de próteses inferior. Concluiu-se que a necessidade de prótese total, tanto superior quanto inferior, mostrou relação com o impacto na qualidade de vida.

DESCRITORES: Qualidade de vida; Saúde bucal; Geriatria; Levantamentos epidemiológicos.
\end{abstract}

\section{INTRODUCTION}

In 1948, the World Health Organization (WHO) defined health as being "complete physical, mental and social well-being, and not merely the absence of diseases or illnesses"17.
With the modifications of the paradigms derived from the evolution of medical practice, it became clear that such a definition lacked some important aspects of the life of individuals. In

\footnotetext{
* PhD in Public Health; **PhD in Preventive and Social Dentistry; ***MSc in Dentistry; ****Undergraduate Students, Scholarship holders; ${ }^{* * * *} \mathrm{MSc}-$ School of Dentistry, Western Santa Catarina University.
} 
Biazevic MGH, Michel Crosato E, Iagher F, Pooter CE, Correa SL, Grasel CE. Impact of oral health on quality of life among the elderly population of Joaçaba, Santa Catarina, Brazil. Braz Oral Res 2004;18(1):85-91.

this sense, Locker ${ }^{9}$ (1997) explains that the term "health" may be defined as the "subjective experience of a person in relation to his functional, social and psychological well-being". Consequently, it refers to the individual experience, and its consequences in everyday life. Therefore, it constitutes a sociological and psychological concept, which may be applied to individuals and populations ${ }^{2}$.

The greatest limitation of traditional epidemiological indicators is their inability to reflect the "capacity of an individual to perform tasks and activities"13. Self-perceived measures convey more information about the way a certain disease is affecting the individual's daily routine and the population in general than the measurements collected from a clinical environment $t^{5}$.

Clinical indicators are important for the assessment of oral health and treatment needs; nevertheless, their limitations must be considered ${ }^{11}$. The combined clinical and subjective indicators define a multi-dimensional assessment of the oral health condition ${ }^{1}$. Locker ${ }^{10}$ (1998) explains that the quality of life indicators related to oral health were defined as the measurements of how much dental problems and oral disorders interfere in the normal functioning of an individual's life. Since the indicators were meant to supply information related to societies, they are inadequate to evaluate individual well-being.

Each population, depending on their life styles, socio-economic status and access to health services, has distinctive experiences about their health condition. Therefore, the purpose of this study was to assess the impact of oral health on the quality of life of the elderly population in the city of Joaçaba, SC, Southern Brazil.

\section{MATERIAL AND METHODS}

The assessment was carried out in Joaçaba, a city in the western region of the State of Santa Catarina, in Southern Brazil. The Oral Health Impact Profile (OHIP) ${ }^{15}$ was used as the instrument to assess the quality of life associated with oral health conditions and was applied through personal interviews; the standard clinical exam for the observation of the use and need of prosthesis was carried out according to the criteria established in the $4^{\text {th }}$ edition of the World Health Organization Manual ${ }^{18}$; the socio-economic breakdown was determined according to the criteria of the Brazilian Association of Market Research Institutes - ABIPEME ${ }^{4}$, level of education and number of residents per household. The information related to the use of health services and of preventive methods was obtained through specific direct questions concerning every health professional visited during the 12 months prior to the questioning, and about every method of oral hygiene used by the participant in the 14 days prior to the interview.

A representative random systematic sampling of clusters from 183 elderly people aged 65 and over was selected from the old age groups of Joaçaba, SC. Previous to the commencement of the research, workshops with the participants were conducted in order to discuss the method of performance of the interviews ${ }^{12}$. A pilot test was done to calibrate the 5 surveyors in relation to the observation of the clinical condition examined, and the (kappa) agreement test was used for these measurements until an adequate value was obtained. For the analysis of the results, the Spearman correlation test was used to verify correlations between OHIP items and use of and need for both maxillary and mandibular prosthesis, OHIP and ABIPEME criteria, OHIP and level of education, and also OHIP and number of residents per household; the Mann-Whitney association test was used to verify the association between the use of and need for maxillary and mandibular prosthesis and ABIPEME criteria and also between the use of and need for maxillary and mandibular prosthesis and the OHIP average. A $5 \%$ significance level was adopted.

\section{RESULTS}

The kappa agreement test result was adequate for the purposes of the study $(\kappa>0.8)$.

The population studied was composed mainly of female individuals (82\%), with average socioeconomic level of 30.98 (maximum possible: 66), and OHIP average of 10.35 (maximum possible: 56). Half of the participants (50\%) are in the $C$ socio-economic class according to the ABIPEME classification methods ${ }^{4}$, followed by the participants from classes D (28.6\%), E (7.7\%), B (5.6\%) and $\mathrm{A}(1.5 \%)$.

Table 1 shows the distribution of the answers to each impact measured by the OHIP. It was noticed that the participants showed low impact of oral problems since the average of each impact measured ranged from 0.16 to 1.51 . Table 1 further shows the frequency distribution of the answers to the items measured by the instrument. Most participants experienced several impacts affecting their daily life: speech (33.4\%), alterations in flavor of foods $(38.3 \%)$, pain $(46.5 \%)$, food intake discomfort $(40.4 \%)$, uneasiness $(42.1 \%)$, stress $(44.8 \%)$, 
Biazevic MGH, Michel Crosato E, Iagher F, Pooter CE, Correa SL, Grasel CE. Impact of oral health on quality of life among the elderly population of Joaçaba, Santa Catarina, Brazil. Braz Oral Res 2004;18(1):85-91.

TABLE 1 - Descriptive statistics of the impact related to each item of the OHIP (Oral Health Impact Profile) among the elderly who belonged to old age groups in the municipality of Joaçaba, SC, in 2002.

\begin{tabular}{|c|c|c|c|c|c|c|c|c|c|c|c|c|}
\hline \multirow[t]{2}{*}{ OHIP } & \multicolumn{2}{|c|}{$\begin{array}{c}0 \\
\text { (never) }\end{array}$} & \multicolumn{2}{|c|}{$\begin{array}{c}1 \\
\text { (hardly ever) } \\
\end{array}$} & \multicolumn{2}{|c|}{$\begin{array}{c}2 \\
\text { (occasioally) }\end{array}$} & \multicolumn{2}{|c|}{$\begin{array}{c}3 \\
\text { (fairly often) }\end{array}$} & \multicolumn{2}{|c|}{$\begin{array}{c}4 \\
\text { (very often) }\end{array}$} & \multirow[t]{2}{*}{ Mean } & \multirow{2}{*}{$\begin{array}{l}\text { Standard } \\
\text { deviation }\end{array}$} \\
\hline & $\mathrm{n}$ & $\%$ & $\mathrm{n}$ & $\%$ & $\mathrm{n}$ & $\%$ & $\mathrm{n}$ & $\%$ & $\mathrm{n}$ & $\%$ & & \\
\hline OHIP 1 item a & 122 & 66.7 & 6 & 3.3 & 40 & 21.9 & 5 & 2.7 & 10 & 5.5 & 0.77 & 1.201 \\
\hline OHIP 2 item b & 113 & 61.7 & 15 & 8.2 & 33 & 18.0 & 8 & 4.4 & 14 & 7.7 & 0.88 & 1.287 \\
\hline OHIP 3 item c & 98 & 53.6 & 19 & 10.4 & 53 & 29.0 & 4 & 2.2 & 9 & 4.9 & 0.95 & 1.166 \\
\hline OHIP 4 item d & 77 & 42.1 & 15 & 8.2 & 43 & 23.5 & 16 & 8.7 & 0 & 0 & 1.51 & 1.526 \\
\hline OHIP 5 item e & 106 & 57.9 & 17 & 9.3 & 38 & 20.8 & 7 & 3.8 & 15 & 8.2 & 0.95 & 1.298 \\
\hline OHIP 6 item $\mathrm{f}$ & 101 & 55.2 & 18 & 9.8 & 46 & 25.1 & 8 & 4.4 & 10 & 5.5 & 0.95 & 1.215 \\
\hline OHIP 7 item $\mathrm{g}$ & 114 & 62.3 & 9 & 4.9 & 33 & 18.0 & 11 & 6.0 & 16 & 8.7 & 0.94 & 1.355 \\
\hline OHIP 8 item $\mathrm{h}$ & 126 & 68.9 & 19 & 10.4 & 23 & 12.6 & 9 & 4.9 & 6 & 3.3 & 0.63 & 1.086 \\
\hline OHIP 9 item i & 144 & 78.7 & 10 & 5.5 & 19 & 10.4 & 5 & 2.7 & 5 & 2.7 & 0.45 & 0.976 \\
\hline OHIP 10 item $\mathrm{j}$ & 112 & 61.2 & 6 & 3.3 & 40 & 21.9 & 11 & 6.0 & 14 & 7.7 & 0.96 & 1.329 \\
\hline OHIP 11 item k & 147 & 80.3 & 7 & 3.8 & 20 & 10.9 & 6 & 3.3 & 3 & 1.6 & 0.42 & 0.928 \\
\hline OHIP 12 item 1 & 167 & 91.3 & 5 & 2.7 & 9 & 4.9 & 2 & 1.1 & 0 & 0 & 0.16 & 0.547 \\
\hline OHIP 13 item m & 133 & 72.7 & 13 & 7.1 & 27 & 14.8 & 3 & 1.6 & 7 & 3.8 & 0.57 & 1.051 \\
\hline OHIP 14 item $\mathrm{n}$ & 170 & 92.9 & 1 & 5.0 & 7 & 3.8 & 3 & 1.6 & 2 & 1.1 & 0.17 & 0.673 \\
\hline
\end{tabular}

a) Have you had trouble pronouncing any words because of problems with your teeth, mouth or dentures?

b) Have you felt that your sense of taste has worsened because of problems with your teeth, mouth or dentures?

c) Have you had painful aching in your mouth?

d) Have you found it uncomfortable to eat any foods because of problems with your teeth, mouth or dentures?

e) Have you felt uncomfortable about the appearance of your teeth, mouth or dentures?

f) Have you felt tense because of problems with your teeth, mouth or dentures?

g) Has your diet been unsatisfatory because of problems with your teeth, mouth or dentures?

h) Have you had to interrupt meals because of problems with your teeth, mouth or dentures?

i) Have you found it difficult to relax because of problems with your teeth, mouth or dentures?

j) Have you been a bit embarrassed because of problems with your teeth, mouth or dentures?

k) Have you been a bit irritable with other people because of problems with your teeth, mouth or dentures?

1) Have you had difficulty doing your usual jobs because of problems with your teeth, mouth or dentures?

m) Have you felt that life in general was less satisfying because of problems with your teeth, mouth or dentures?

n) Have you been totally unable to function because of problems with your teeth, mouth or dentures?

reduction in food intake (37.6\%), interruption of meals $(31.2 \%)$, embarrassment $(38.9 \%)$, among others. The items that presented low impact were those related to the daily tasks performed by the participants (items 12 and 14).

In relation to the distribution of the elderly participants in this survey and the reported oral health impact, it was observed that the higher the socio-economic level the higher the OHIP: among the participants from class A, 21.67\% experienced negative impacts related to their oral condition, followed by class B (13.09\%), C (10.98\%), D (9.31\%) and $\mathrm{E}(4.58 \%)$. It was observed that there is a weak statistically significant correlation between OHIP and ABIPEME (correlation coefficient of 0.240 , $\mathrm{p}=0.001$ ); and there was no correlation between OHIP and level of education (correlation coefficient of $0.103, p=0.182$ ) and between OHIP and number of residents per household (correlation coefficient of $0.118, p=0.125$ ).

The great majority of the participants reported having incomplete elementary education $(55 \%)$ or complete elementary education (35\%); the average impact of the oral condition related to the level of education was similar for the different education levels reported: the participants who had not completed grade school showed an average OHIP of 11.21; for participants who had complete grade school and incomplete junior high school, the average was 9.85; for the group with complete junior high school and incomplete high school education, it was 5.4 points and, finally, high school graduates and incomplete college education, had a 10.5 average. In relation to household popula- 
Biazevic MGH, Michel Crosato E, Iagher F, Pooter CE, Correa SL, Grasel CE. Impact of oral health on quality of life among the elderly population of Joaçaba, Santa Catarina, Brazil. Braz Oral Res 2004;18(1):85-91.

tion, we found that $8 \%$ of the surveyed population lived alone; that there were two residents in $42 \%$ of the homes; that there were three residents in $29 \%$, and four or more residents in the remaining households.

Concerning the distribution of the elderly population in Joaçaba - SC and the use of maxillary prosthesis, we observed that the great majority of the surveyed population $(82.5 \%)$ used total maxillary prosthesis. In relation to the need to use prosthesis, we found that most participants did not need maxillary prosthesis $(68.3 \%)$, and that $21.3 \%$ needed total maxillary prosthesis.

Concerning the use of and the need for mandibular prosthesis, we observed that half $(50.3 \%)$ of the population surveyed use total prosthesis, and that a significant number did not use mandibular prosthesis $(34.4 \%)$. In relation to the need to use mandibular prosthesis, almost half $(47 \%)$ did not show any need, some showed the need for a single prosthesis $(1.6 \%)$, some the need for a prosthesis with several elements (12\%), some the need for single and multiple prosthesis (1.4\%) and some, finally, the need for total prosthesis (19.7\%).

Table 2 shows that there are no statistically significant differences between the use of and the need for either maxillary or mandibular prosthesis and the socio-economic level. This table also shows that there are no statistically significant differences between self-perceived oral health and the use of either maxillary or mandibular prosthesis. Nevertheless, a significant difference was found between the need for prosthesis and the OHIP, for both maxillary and mandibular arches.

Table 3 shows the correlation between some items of the OHIP and the use of and need for prosthesis. The impacts "Have you felt uncomfortable about your teeth, mouth or dentures?" (OHIP 5 item), "Have you been a bit embarrassed because of problems with your teeth, mouth or dentures?" (OHIP 10 item ), "Have you been a bit irritable with other people because of problems with your teeth, mouth or dentures?" (OHIP 11 item) and "Have you been unable to function because of problems with your teeth, mouth or dentures?" (OHIP 14 item) presented a correlation with the use of mandibular prosthesis. Concerning the need for prosthesis, OHIP 11 item also showed impact related to the need for both maxillary and mandibular prosthesis. Furthermore, as far as the need of mandibular prosthesis is concerned, other items of the instrument used must be emphasized, as such "Have you felt tense because of problems with your teeth, mouth or dentures?" (OHIP 6 item) and "Have you been unable to function because of problems with your teeth, mouth or dentures?" (OHIP 14 item).

Referring to the demand for dental services during the 12 months preceding the questioning, the vast majority $(77.6 \%)$ reported not having sought these professional services. There was not any significant statistical difference between the group that sought medical services $(\mathrm{p}=0.471)$ and dental services $(p=0.876)$ and the self-perceived oral health, and the group that did not seek such services.

Most of the participants in this study reported the use of toothbrushes $(97.8 \%)$, dental floss (87.4\%), toothpick (51.4\%), toothpaste (93.4\%), and a few performed mouth rinses $(7.7 \%)$ or topical use of fluoride (1.6\%).

\section{DISCUSSION}

The socio-economic level of population groups

TABLE 2 - Distribution of the elderly who belonged to old age groups in the municipality of Joaçaba, SC, in 2002, as per need for and use of prosthesis, socioeconomic condition (ABIPEME criterion) and self-perceived oral health (OHIP).

\begin{tabular}{|c|c|c|c|c|}
\hline & $\begin{array}{l}\text { Necessity } \\
\text { and use }\end{array}$ & $\begin{array}{c}\text { ABIPEME } \\
\text { average }\end{array}$ & $\mathrm{n}$ & $\mathrm{p}$ \\
\hline \multirow{4}{*}{ Maxillary } & Uses & 26.37 & 19 & \multirow{2}{*}{0.163} \\
\hline & Does not use & 31.80 & 164 & \\
\hline & Does not need & 31.03 & 125 & \multirow{2}{*}{0.739} \\
\hline & Needs & 31.61 & 54 & \\
\hline \multirow{5}{*}{ Mandibular } & Uses & 31.13 & 63 & \multirow{2}{*}{0.679} \\
\hline & Does not use & 31.25 & 120 & \\
\hline & Does not need & 31.08 & 86 & \multirow{2}{*}{0.612} \\
\hline & Needs & 31.34 & 91 & \\
\hline & $\begin{array}{l}\text { Necessity } \\
\text { and use }\end{array}$ & $\begin{array}{c}\text { OHIP } \\
\text { average }\end{array}$ & $\mathrm{n}$ & $\mathrm{p}$ \\
\hline \multirow{4}{*}{ Maxillary } & Uses & 12.47 & 19 & \multirow{2}{*}{0.399} \\
\hline & Does not use & 9.81 & 160 & \\
\hline & Does not need & 8.88 & 124 & \multirow{2}{*}{$0.014^{*}$} \\
\hline & Needs & 13.00 & 51 & \\
\hline \multirow{4}{*}{ Mandibular } & Uses & 12.04 & 116 & \multirow{2}{*}{0.091} \\
\hline & Does not use & 9.17 & 176 & \\
\hline & Does not need & 7.94 & 84 & \multirow{2}{*}{$0.006^{*}$} \\
\hline & Needs & 12.20 & 89 & \\
\hline
\end{tabular}

* Statistically significant. ABIMEPE: Brazilian Association of Market Research Institutes. OHIP: Oral Health Profile Impact. 
Biazevic MGH, Michel Crosato E, Iagher F, Pooter CE, Correa SL, Grasel CE. Impact of oral health on quality of life among the elderly population of Joaçaba, Santa Catarina, Brazil. Braz Oral Res 2004;18(1):85-91.

measured through ABIPEME showed that, on several occasions, it supplies a list of consumer habits of a certain community, and not specifically their socio-economic level. As several studies have used this classification, we opted for using it in this present study, carefully adding some other indicators of socio-economic level, such as the number of residents per household, and the level of education of the population being surveyed. Therefore, we can affirm that the impact of oral condition on the quality of life of the population, the subject of this study, showed little relation with their socio- economic condition, if taken into account only the last two indicators mentioned above. Concerning the correlation showing that the higher the level of consumption the higher the OHIP, one could suggest that people with higher consumption standards tend to be more critical about the perception of their oral health, especially if we observe that the great majority of the population studied did not seek dental services during the 12 months prior to the survey. This point requires further studies in the future.

The need for prosthesis confirmed by objective

TABLE 3 - Correlation of OHIP items with use of and need for prosthesis among the elderly who belonged to old age groups in the municipality of Joaçaba, SC, in 2002.

\begin{tabular}{|c|c|c|c|c|c|}
\hline & & $\begin{array}{l}\text { Use of maxillary } \\
\text { prosthesis }\end{array}$ & $\begin{array}{l}\text { Need of maxil- } \\
\text { lary prosthesis }\end{array}$ & $\begin{array}{l}\text { Use of mandibu- } \\
\text { lar prosthesis }\end{array}$ & $\begin{array}{l}\text { Need of mandib- } \\
\text { ular prosthesis }\end{array}$ \\
\hline \multirow{2}{*}{ OHIP 1 item } & $\mathrm{cc}$ & -0.030 & 0.088 & -0.094 & 0.021 \\
\hline & Significance (2-tailed) & 0.686 & 0.238 & 0.206 & 0.779 \\
\hline \multirow{2}{*}{ OHIP 2 item } & $\mathrm{cc}$ & 0.034 & 0.042 & -0.078 & 0.080 \\
\hline & Significance (2-tailed) & 0.648 & 0.572 & 0.293 & 0.280 \\
\hline \multirow{2}{*}{ OHIP 3 item } & $\mathrm{cc}$ & 0.021 & 0.067 & -0.031 & 0.116 \\
\hline & Significance (2-tailed) & 0.777 & 0.371 & 0.679 & 0.118 \\
\hline \multirow{2}{*}{ OHIP 4 item } & $\mathrm{cc}$ & 0.070 & 0.173 & 0.027 & 0.077 \\
\hline & Significance (2-tailed) & 0.345 & 0.019 & 0.717 & 0.302 \\
\hline \multirow{2}{*}{ OHIP 5 item } & cc & -0.059 & 0.150 & -0.191 & 0.116 \\
\hline & Significance (2-tailed) & 0.426 & 0.042 & $0.010^{*}$ & 0.117 \\
\hline \multirow{2}{*}{ OHIP 6 item } & $\mathrm{cc}$ & 0.002 & 0.167 & -0.172 & 0.201 \\
\hline & Significance (2-tailed) & 0.980 & 0.024 & 0.020 & $0.006^{*}$ \\
\hline \multirow{2}{*}{ OHIP 7 item } & $\mathrm{cc}$ & 0.007 & 0.142 & -0.043 & 0.185 \\
\hline & Significance (2-tailed) & 0.921 & 0.054 & 0.559 & 0.012 \\
\hline \multirow{2}{*}{ OHIP 8 item } & $\mathrm{cc}$ & 0.071 & 0.047 & -0.027 & 0.103 \\
\hline & Significance (2-tailed) & 0.341 & 0.526 & 0.722 & 0.167 \\
\hline \multirow{2}{*}{ OHIP 9 item } & $\mathrm{cc}$ & 0.018 & 0.066 & -0.040 & 0.086 \\
\hline & Significance (2-tailed) & 0.811 & 0.374 & 0.586 & 0.250 \\
\hline \multirow{2}{*}{ OHIP 10 item } & $\mathrm{cc}$ & -0.100 & 0.168 & -0.278 & 0.162 \\
\hline & Significance (2-tailed) & 0.180 & 0.023 & $0.000^{*}$ & 0.029 \\
\hline \multirow{2}{*}{ OHIP 11 item } & cc & -0.005 & 0.218 & -0.197 & 0.314 \\
\hline & Significance (2-tailed) & 0.946 & $0.003^{*}$ & $0.008^{*}$ & $0.000^{*}$ \\
\hline \multirow{2}{*}{ OHIP 12 item } & $\mathrm{cc}$ & 0.087 & 0.153 & -0.139 & 0.171 \\
\hline & Significance (2-tailed) & 0.244 & 0.039 & 0.062 & 0.021 \\
\hline \multirow{2}{*}{ OHIP 13 item } & $\mathrm{cc}$ & 0.096 & -0.022 & -0.173 & 0.161 \\
\hline & Significance (2-tailed) & 0.195 & 0.766 & 0.019 & 0.029 \\
\hline \multirow{2}{*}{ OHIP 14 item } & $\mathrm{cc}$ & 0.010 & 0.144 & -0.213 & 0.199 \\
\hline & Significance (2-tailed) & 0.894 & 0.052 & $0.004^{*}$ & $0.007^{*}$ \\
\hline
\end{tabular}

*Statistically significant; cc: correlation coefficient. OHIP: Oral Health Impact Profile. 
Biazevic MGH, Michel Crosato E, Iagher F, Pooter CE, Correa SL, Grasel CE. Impact of oral health on quality of life among the elderly population of Joaçaba, Santa Catarina, Brazil. Braz Oral Res 2004;18(1):85-91.

examinations showed that it increases the negative impact on self-perceived oral health, a fact not associated with the use of medical and/or dental services.

When Slade, Spencer ${ }^{15}$ (1994) carried out research to validate the "Oral Health Impact Profile" (OHIP) instrument in Southern Australia, they observed that the OHIP was able to detect a previously observed association between social impact and the perceived need for treatment.

Cushing et al. ${ }^{3}$ (1986) found positive correlation between food intake problems and discomfort with teeth, for both genders. The authors also found an association between the non-satisfaction with the aspects of their teeth and restrictions in communication. In an epidemiological assessment of oral health carried out in Canada, Slade et al. $^{14}$ (1990) found several impacts in the performance of daily activities derived from oral health conditions. The authors stated that one third of the elderly people reported oral-facial pain, 50\% reported difficulties in chewing food and 30\% reported some other impact resulting from their oral health, mainly: avoiding certain foods, embarrassment derived from their appearance or their oral health, avoiding smiling or laughing, despite the fact that only $2 \%$ stated that their oral health had impaired their social contact with people.

Upon observing any impact of the oral health condition associated with the need for prosthesis, it was noted that the access to health services could be related to this finding. As most of the participants reported not having looked for dental services lately, it could be suggested that access to such services in the area is precarious. Assessing the need for treatments of 254 elderly English individuals, Smith, Sheiham ${ }^{16}$ (1980) found that these people were facing several limitations in their

\section{REFERENCES}

1. Biazevic MGH. Indicadores subjetivos em saúde bucal: revisão sistemática [Dissertação de Mestrado]. São Paulo: Faculdade de Odontologia da USP; 2001.

2. Buss PM (coord.). Promoção da saúde e a saúde pública. Contribuição para o debate entre as escolas de saúde pública da América Latina. Rio de Janeiro: mimeo; 1998. p. $1-15$

3. Cushing AM, Sheiham A, Maizels J. Developing sociodental indicators - the social impact of dental disease. Community Dent Health 1986;3:3-17.

4. Gil AC. Métodos e técnicas de pesquisa social. São Paulo: Atlas; 1999.

5. Gilbert GH, Duncan RP, Heft MW, Dolan TA, Vogel WB. Multidimensionality of oral health in dentate adults. Med daily activities derived from their oral condition, and the search for dental treatment was very low, in spite of the great self-perceived and confirmed need for treatment.

In a group of 662 Brazilian adults, Leão, Sheiham $^{6,7,8}(1995,1997,1996)$ tested the instrument "Subjective Impacts on Daily Living" (DIDL). They observed a weak, but significant, association between oral health and the socio-psychological measures applied. Lost or decayed teeth presented a significant negative association in all aspects verified, except for the "comfort" impact. The authors explained that this indicates that as the number of lost or decayed teeth decreases, the scores set for the dimensions studied (comfort, appearance and food restrictions) increase; people become more satisfied with their oral condition. In this same study, filled teeth showed a positive association with the "performance" dimension.

\section{CONCLUSIONS}

The results of this study indicated that: the impact of oral health on the quality of life of the participants tended to be greater for people with better socio-economic conditions; most of the participants reported to have faced several impacts on their daily life as a consequence of their oral condition; the socio-economic factor did not show any relation to the use of either maxillary or mandibular prosthesis; there were no differences between self-perceived oral health and the use of either maxillary or mandibular prosthesis; there is a relation between the need for prosthesis and the OHIP, for both maxillary and mandibular arches; and the impact of the oral condition on the quality of life was not related to the use of medical or dental services.

Care 1998;36:988-1001.

6. Leão A, Sheiham A. Relation between clinical dental status and subjective impacts on daily living. J Dent Res 1995;74:1408-13.

7. Leão A, Sheiham A. The dental impact on daily living. In: Slade G. Measuring oral health and quality of life. Chapel Hill: University of North Carolina, Dental Ecology; 1997. p. 121-34

8. Leão A, Sheiham A. The development of a socio-dental measure of dental impacts on daily living. Community Dent Health 1996;13:22-6.

9. Locker D. Concepts of oral health, disease and the quality of life. In: Slade G. Measuring oral health and quality of life. Chapel Hill: University of North Carolina, Dental 
Biazevic MGH, Michel Crosato E, Iagher F, Pooter CE, Correa SL, Grasel CE. Impact of oral health on quality of life among the elderly population of Joaçaba, Santa Catarina, Brazil. Braz Oral Res 2004;18(1):85-91.

Ecology; 1997. p. 11-24.

10. Locker D. Issues in measuring change in self-perceived oral health status. Community Dent Oral Epidemiol 1998;26:41-7.

11. Locker D, Miller Y. Subjectively reported oral health status in an adult population. Community Dent Oral Epidemiol 1994;22:425-30.

12. Oppenheim AM. Questionnaire design, interviewing and attitude measurement. London: Pinter; 1993.

13. Reisine ST. The impact of dental conditions on social functioning and the quality of life. Annu Rev Public Health 1988;9:1-19.

14. Slade GD, Locker D, Leake JL, Wu ASM, Dunkley G. The oral health status and treatment needs of adults aged 65+ living independently in Ottawa-Carleton. Can J Public Health 1990;81:114-9.

15. Slade GD, Spencer AJ. Development and evaluation of the Oral Health Impact Profile. Community Dent Health 1994;11:3-11.

16. Smith JM, Sheiham A. Dental treatment needs and demands of an elderly population in England. Community Dent Oral Epidemiol 1980;8:360-4.

17. World Health Organization. Basic documents. 10th ed. Geneva: OMS; 1960.

18. World Health Organization. Oral health surveys: basic methods. 4th ed. Geneva: OMS; 1998.

Received for publication in Nov 03, 2003

Sent for alterations in Jan 14, 2004

Accepted for publication in Mar 01, 2004 